\title{
Suboxone Prescribing Availability in Orange County, NY
}

\author{
Supriya Makam, Clifford Gevirtz, Judith Branche, Kevin Sperber, Edward Alexeev \\ Einstein-Montefiore Medical Center, Cornerstone Family Healthcare, Newburgh, NY, USA \\ Email: supriyam630@gmail.com
}

How to cite this paper: Makam, S., Gevirtz, C., Branche, J., Sperber, K. and Alexeev, E. (2017) Suboxone Prescribing Availability in Orange County, NY. Open Journal of Anesthesiology, 7, 331-340. https://doi.org/10.4236/ojanes.2017.710033

Received: August 9, 2017

Accepted: October 14, 2017

Published: October 17, 2017

Copyright ( 92017 by authors and Scientific Research Publishing Inc. This work is licensed under the Creative Commons Attribution International License (CC BY 4.0).

http://creativecommons.org/licenses/by/4.0/ (c) (i) Open Access

\begin{abstract}
Background: The opioid epidemic is a major threat to public health in the United States of America. Orange County, New York has been chosen for this study of Suboxone, a prescription medicine that is used to treat addiction to opioid analgesics. This drug is underutilized throughout Orange County because of several impediments, including insurance coverage, social stigmas, and a non-compliant patient population. Objective: The objective is to analyze the accessibility and utilization of Suboxone to treat opioid dependence in Orange County, New York. Method: Two survey instruments have been created for this research project, one for Suboxone providers and one for nonSuboxone providers. Each is 10 questions long, and includes multiple choice and open-response questions. Participants were contacted by means of email and telephone. Results: The results displayed that many Suboxone providers prefer not treating this patient population for the following reasons: insurance coverage problems, lack of time to see these demanding patients, and a non-compliant patient population. Almost all of the doctors surveyed believed that there is a social stigma among physicians to prescribe as well as among patients to use Suboxone. The non-Suboxone providers did not want to prescribe Suboxone because of a non-compliant patient population, and not having enough time in their practice. Almost all of the non-Suboxone providers prescribed other opiates. For most of the doctors, having more ancillary staff (psychologists, physical therapists, mid level providers) would motivate them to prescribe Suboxone. Discussion and Conclusion: Recommendations made by the local physicians for treating the current opioid epidemic include the following: more police enforcement of street drug dealers, patient education of narcotic misuse, physician education of both the opioid epidemic and patient treatment, and expanding access to rehabilitation and care for these patients.
\end{abstract}

\section{Keywords}

Suboxone Utilization, NY, Opioid Abuse, Suboxone Prescribers, Addiction 


\section{Introduction}

Currently, the opioid epidemic is a major crisis in the United States. "In 2014 alone, approximately 28,647 deaths occurred nationally due to prescription opioid overdoses, with 2300 of those deaths, roughly 8 percent, in New York State. In 2013, 1601 people died in New York State from an opioid related overdose ... This shocking loss of life to heroin and opioid drugs, an average of two deaths per day, demonstrates a death rate $68.7 \%$ higher than in 2008." [1] "Since the beginning of the year, there have been at least 15 confirmed and 18 suspected overdose deaths in Orange County (New York), with about 70 deaths last year." [2] Current solutions to this problem include Suboxone and Zubsolv (buprenorphine/naloxone combinations), Vivitrol (an extended-release naltrexone), and methadone. Though these treatments have had much success, there are still many problems, including limited access, lack of treatment programs, and poor insurance coverage of the drugs [2]. An additional hurdle to diminishing the opioid epidemic includes the unwillingness of doctors to prescribe these drugs. "In the US, only $49 \%$ of people with an opioid dependence can potentially receive treatment because too few doctors prescribe the medicine (Suboxone), and those that do can serve only a limited number of patients because of federal restrictions." [3] Effective August $5^{\text {th }}, 2016$, the federal government raised the limit of opioid dependent patients that doctors can treat with Suboxone from 200 to 275 [4]. However, with not enough providers and treatment centers, the opioid epidemic is still rampant across Orange County, NY. To compile the data, 32 doctors were surveyed using two 10-question instruments: one survey for Suboxone providers, and another survey for non-Suboxone providers. This approach was taken to find out why doctors in Orange County, NY are unwilling to treat more Suboxone patients or take the certification course to be able to provide the drug. Though there are over 1000 physicians and physician's assistants in Orange County that are eligible to take the certification course, there are only about 25 Suboxone providers in the area [5] [6]. The main goal of this research project was to understand why majority of doctors in this county do not wish to prescribe Suboxone.

\section{Method}

Participants were contacted by means of email and telephone (Table $1 \&$ Table 2).

\section{Results}

Demographics of the participants are all of the physicians in Orange County, NY who are registered to prescribe Suboxone, and all of those who are not registered.

The population size (N), for Table 3, was determined by the Substance Abuse and Mental Health Services Administration (SAMHSA) registry [6]. There are 25 Suboxone providers in Orange County, New York. The sample size (n) is 7. The response rate was $88 \%$. The majority of Suboxone providers prescribed 
Table 1. Survey Instrument of Suboxone Providers.

Completion Time: 5 - 7 minutes

Questions $\quad$ Responses

1. Why do you prescribe Suboxone?

a. Helps patients, the community, and society

b. Increases number of patients in practice

c. Other: please specify

2. Do you prescribe other opioid medications to your patients?

a. Yes

b No

3. Do you screen for opioid dependence in your practice?
a. Yes
b. No
c. Prefer not to answer

4. Are you aware of the opioid risk tool?
a. Yes
b. No

5. Do you think the insurance coverage of Suboxone is a problem a. Yes for the patients?

b. No

6. Where would you send your patients if they wanted to seek treatment for their opioid addiction?

7. Do you think there is a social stigma among doctors to prescribe a. Yes Suboxone?

b. No

8. Do you think there is a social stigma among patients when a. Yes taking Suboxone?

b. No

9. How many Suboxone patients do you have?
a. 0 - 30
b. $30-200$
c. $200-275$

10. What are the impediments of treating more patients?
a. Insurance coverage
b. Not enough time
c. Non-compliant patient population
d. Not enough reimbursement
e. Other: please specify

11. What would motivate you to treat more Suboxone patients?
a. No response
b. Better reimbursement
c. Better insurance coverage
d. More ancillary staff (psychologists, physical therapists, other therapists)
e. Having mid-level providers (physician's assistants and nurse practitioners)
f. Other: please specify

12. How would you recommend treating the current opioid epidemic in Orange County, New York? 
Table 2. Survey Instrument of Non-Suboxone Providers.

Completion Time: 5 - 7 minutes

Questions $\quad$ Responses

1. Why don't you prescribe Suboxone?
a. Inadequate reimbursement for time and effort involvement
b. Not enough time to take in addiction patients
c. Believe that treatment is not beneficial
d. Non-compliant patient population
e. Rules and regulations doctors are required to follow when prescribing opioids
f. Other: please specify

2. Do you prescribe other opioid medications to your patients?
a. Yes
b. No

3. If yes (to the previous question), for what diagnoses, and how do you monitor these patients?

4. Do you think you have substance abuse in your practice?
a. Yes
b. No
c. Prefer not to answer

5. Do you screen for opioid dependence in your practice?
a. Yes
b. No
c. Prefer not to answer

6. Do you think the insurance coverage of Suboxone is a problem for the patients?
a. Yes
b. No
c. Don't Know

7. Where would you send your patients if they wanted to seek treatment for their opioid addiction?

8. Do you think there is a social stigma among doctors to prescribe Suboxone?
a. Yes
b. No
c. Don't Know

9. Do you think there is a social stigma among patients when taking Suboxone?
a. Yes
b. No
c. Don't Know

10. What would motivate you to treat Suboxone patients?
a. Better reimbursement
b. Better insurance coverage
c. More ancillary staff (psychologists, physical therapists, other therapists)
f. Having mid-level providers (physician's assistants and nurse practitioners)
e. Other: please specify

11. How would you recommend treating the current opioid epidemic in Orange County, New York? 
Table 3. Survey Instrument of Suboxone Providers.

\begin{tabular}{ll}
\hline Questions & Responses \\
\hline
\end{tabular}

1. Why do you prescribe Suboxone?
a. Helps patients, the community, and society $=6(86 \%)$
b. Increases number of patients in practice $=0(0 \%)$
c. Other: please specify $=1$ (effective treatment) $(14 \%)$

2. Do you prescribe other opioid medications to your patients?*

a. $\quad$ No response $=1(14 \%)$

b. Yes $=5(71 \%)$

c. $\mathrm{No}=1(14 \%)$

3. Do you screen for opioid dependence in your practice?

a. $\mathrm{Yes}=6(86 \%)$

b. No $=1(14 \%)$

c. Prefer not to answer $=0(0 \%)$

4. Are you aware of the opioid risk tool?
a. $\quad$ Yes $=7(100 \%)$
b. $\mathrm{No}=0(0 \%)$
a. $\quad$ Yes $=5(71 \%)$
b. $\mathrm{No}=2(29 \%)$

5. Do you think the insurance coverage of Suboxone is a problem for the patients?

6. Where would you send your patients if they wanted to seek treatment for their opioid addiction?

- $\quad$ No response $=2(29 \%)$

- St. Christopher's Rehabilitation St. Francis Rehabilitation

- In patient psychiatric or rehabilitation center

- Orange Regional Medical Center

- Outpatient rehabilitation program

7. Do you think there is a social stigma among doctors to prescribe Suboxone?
a. Yes $=6(86 \%)$
b. $\mathrm{No}=1(14 \%)$

8. Do you think there is a social stigma among patients when taking Suboxone?

a. Yes $=7(100 \%)$

b. $\mathrm{No}=0(0 \%)$

9. How many Suboxone patients do you have?
a. $\quad$ No response $=1(14 \%)$
b. $0-30=2(29 \%)$
c. $30-200=3(43 \%)$
d. $200-275=1(14 \%)$

10. What are the impediments of treating more patients?
a. Insurance coverage $=1(14 \%)$
b. Not enough time $=2(29 \%)$
c. Non-compliant patient population $=3(43 \%)$
d. Not enough reimbursement $=0(0 \%)$
e. Other: please specify $=1$ (no problems) $(14 \%)$

11. What would motivate you to treat more Suboxone patients?
a. $\quad$ No response $=1(14 \%)$
b. Better reimbursement $=2(29 \%)$
c. Better insurance coverage $=2(29 \%)$
d. More ancillary staff (psychologists, physical therapists, other therapists) $=0(0 \%)$
e. Having mid-level providers (physician's assistants and nurse practitioners $)=0(0 \%)$
f. Other: please specify $=2$ (don't need motivation + more patient education) $(29 \%)$ 


\section{Continued}

12. How would you recommend treating the current opioid epidemic in Orange County, New York?

- More treatment availability

- More government funding

- More patient education and awareness

- More police enforcement of addicts into rehab programs than in jail

- More elimination of street dealers

- More rehabilitation

- Strict enforcement and immediate action

- Educating youth

- Prevention-avoid having to treat these patients

- Education to providers and consumers of healthcare

- Expand access to care

- Provide easy access and transport for patients to reach treatment clinics

- Encourage physicians to routinely screen for addiction

- Limit prescribing opiates for pain issues and limit quantity dispensed

- Make people (especially young adults) aware that there is treatment available in an outpatient setting where they can go discreetly-this would remove the negative social stigma attached to such treatment

- Increase insurance coverage for both doctor visits and medications

*-Because seven doctors were interviewed, everything has been rounded to the nearest whole percentage.

Suboxone because they believed that it helps patients, the community, and the society. Many of these doctors also prescribed other opioid medications to their patients, and screened for opioid dependence in their practice. All of the doctors were aware of the opioid risk tool, and most of these doctors believed that insurance coverage of Suboxone was a problem. If their patients wanted to seek treatment for their opioid addiction, these doctors would send them to local rehabilitation facilities or hospitals. Almost all doctors agreed that there is a social stigma among doctors to prescribe Suboxone, and that there is a social stigma among patients when taking Suboxone. In the survey $29 \%$ of the doctors had a very low number of Suboxone patients, $43 \%$ are building up their practice, and only one physician has close to the maximum number of Suboxone patients. Some doctors believed that the impediments of seeing more Suboxone patients included not having enough time, and a non-compliant patient population. Better reimbursement and insurance coverage, and improved patient education would motivate these doctors to see more Suboxone patients. Recommendations for treating the current opioid epidemic in Orange County, NY include more treatment availability and rehabilitation, additional patient education, limiting the prescription of opiates, and increasing insurance coverage for Suboxone.

The population size (N), for Table 4, was determined by the New York State Education Department [5]. There are estimated to be 1167 physicians and physician's assistants in Orange County, New York. The sample size (n), is 25. The response rate was $100 \%$. Majority of the non-Suboxone providers did not pre- 
Table 4. Survey Instrument of Non-Suboxone Providers.

\begin{tabular}{|c|c|}
\hline Questions & Responses \\
\hline 1. Why don't you prescribe Suboxone? & $\begin{array}{l}\text { a. Inadequate reimbursement for time and effort involvement }=1(4 \%) \\
\text { b. Not enough time to take in addiction patients }=6(24 \%) \\
\text { c. Believe that treatment is not beneficial }=0(0 \%) \\
\text { d. Non-compliant patient population }=11(44 \%) \\
\text { e. Rules and regulations doctors are required to follow when prescribing opioids = } 5 \\
\text { f. Other: please specify = } 1 \text { (haven't yet taken certification course) }(4 \%) 1 \text { (don't have } \\
\text { patients who need it) (4\%) }\end{array}$ \\
\hline $\begin{array}{l}\text { 2. Do you prescribe other opioid medications to } \\
\text { your patients? }\end{array}$ & $\begin{array}{l}\text { a. } \quad \text { Yes }=23(92 \%) \\
\text { b. } \quad \text { No }=2(8 \%)\end{array}$ \\
\hline $\begin{array}{l}\text { 3. If yes (to the previous question), for what } \\
\text { diagnoses, and how do you monitor these } \\
\text { patients? }\end{array}$ & $\begin{array}{l}\text { a. Do not prescribe }=2(8 \%) \\
\text { b. No response }=1(4 \%) \\
\text { c. For acute and chronic, severe pain } \\
\text { d. Postop surgical pain } \\
\text { e. Cancer } \\
\text { f. Arthritis } \\
\text { g. Chronic conditions with medical backing } \\
\text { h. Back pain and cancer patients } \\
\text { i. Knee, hip, shoulder pain } \\
\text { j. Musculoskeletal disorders } \\
\text { Monitoring: } \\
\text { - Urine testing and drug screening } \\
\text { - Random drug testing } \\
\text { - Monthly visits } \\
\text { - NYS Prescription Monitoring program } \\
\text { - Random medication counting } \\
\text { - Frequent follow up appointments }\end{array}$ \\
\hline $\begin{array}{l}\text { 4. Do you think you have substance abuse in } \\
\text { your practice? }\end{array}$ & $\begin{array}{l}\text { a. } \text { Yes }=16(64 \%) \\
\text { b. No }=7(28 \%) \\
\text { c. Prefer not to answer = } 2(8 \%)\end{array}$ \\
\hline $\begin{array}{l}\text { 5. Do you screen for opioid dependence in your } \\
\text { practice? }\end{array}$ & $\begin{array}{l}\text { a. Yes }=18(72 \%) \\
\text { b. No }=6(24 \%) \\
\text { c. Prefer to answer }=1(4 \%)\end{array}$ \\
\hline $\begin{array}{l}\text { 6. Do you think the insurance coverage of } \\
\text { Suboxone is a problem for the patients? }\end{array}$ & $\begin{array}{l}\text { a. } \text { Yes }=12(48 \%) \\
\text { b. No }=7(28 \%) \\
\text { c. Don't Know }=6(24 \%)\end{array}$ \\
\hline $\begin{array}{l}\text { 7. Where would you send your patients if they } \\
\text { wanted to seek treatment for their opioid } \\
\text { addiction? }\end{array}$ & $\begin{array}{l}\text { - } \\
\text { - } \text { Do response }=4(16 \%) \\
-\quad \text { Pain clinic } \\
-\quad \text { Cornerstone Famility Health Center in Newburgh, NY } \\
-\quad \text { Turning Point Rehabilitation } \\
-\quad \text { Orange Regional Medical Center } \\
-\quad \text { Active detox center } \\
-\quad \text { Catholic Charities }\end{array}$ \\
\hline
\end{tabular}




\section{Continued}

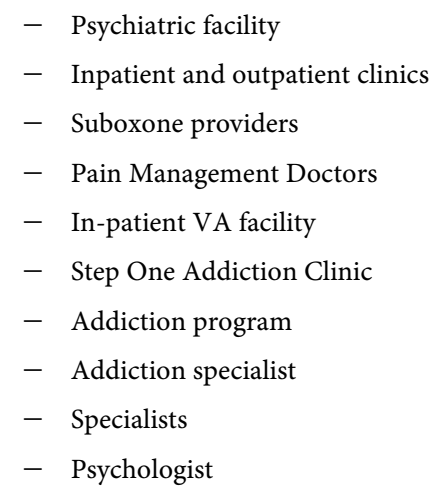

8. Do you think there is a social stigma among doctors to prescribe Suboxone?

a. Yes $=15(60 \%)$

b. $\mathrm{No}=9(36 \%)$

c. Don't Know $=1(4 \%)$

9. Do you think there is a social stigma among patients when taking Suboxone?

a. Yes $=18(72 \%)$

b. $\mathrm{No}=6(24 \%)$

c. Don't Know $=1(4 \%)$

10. What would motivate you to treat Suboxone patients?

a. $\quad$ No response $=2(8 \%)$

b. Better reimbursement $=4(16 \%)$

c. Better insurance coverage $=3(12 \%)$

d. More ancillary staff (psychologists, physical therapists, other therapists) $=9(36 \%)$

e. Having mid-level providers (physician's assistants and nurse practitioners) $=1(4 \%)$

f. Other: please specify $=3$ (nothing, just don't have the time) (12\%)

3 (don't want to be a part of it) (12\%)

11. How would you recommend treating the current opioid epidemic in Orange County, New York?

- No response $=3(12 \%)$

- More education and more government funded facilities

- More Suboxone doctors

- Get to the source

- Drug education

- Further education of doctors

- Fixing deep social stigmas

- More Pain Management clinics

- Insurance plans covering narcotics for a longer time

- Stricter prescription guidelines for opioids

- More frequent drug screening

- More counseling for psychiatric issues

- More government enforcement of controlling street drugs

- Making sure that only pain management doctors can prescribe opiates

- More education on drug addiction

- Fixing stigmas associated with opiate addiction and treatment

- Finding alternatives to opioids when prescribing pain medications

- Patient education to non-opioid alternatives

- More monitoring and drug testing to ensure compliance

- Refer patients to addiction specialists

- Plan for a substitute or eventually no need for the opioid 
scribe Suboxone because they did not want to deal with this type of patient population. Almost all of the physicians prescribed other opioid medications, mainly for chronic pain and arthritis. They also monitored these patients with frequent follow up visits, random drug and urine testing, and the New York State Prescription Monitoring program. Majority of these doctors believed that there is substance abuse in their practice, and $72 \%$ screened for opioid dependence. Though almost $50 \%$ of the doctors believed that insurance coverage of Suboxone was a problem for the patients, a quarter of the doctors did not think that insurance coverage was a problem, and another quarter did not know if it was an issue. If patients wanted to seek treatment for their opioid addiction, physicians would send them to pain management doctors, addiction specialists, or local rehabilitation facilities. More than half of the doctors believed that there was a social stigma among doctors who prescribe Suboxone, whereas the other $40 \%$ thought that there wasn't a stigma or did not know. However, majority of the doctors thought that there was a social stigma among patients when taking Suboxone. For most of the physicians, having more ancillary staff (psychologists, physical therapists, mid level providers) would motivate them to prescribe Suboxone. Recommendations for treating the current opioid epidemic in Orange County, NY include patient and doctor education on opioids, more drug screening and patient monitoring, and finding alternatives to opioids when prescribing pain medications.

\section{Discussion}

Some hurdles in collecting the data included reaching out to Suboxone providers, as there are not many in the area. Furthermore, many of the non-providers did not know how to answer certain questions on the survey, as they were not familiar with those topics (such as insurance coverage and social stigmas). From the data collected, it is clear that providers should be in major treatment facilities instead of in small private practices, as these providers would be less affected by the insurance coverage problems of Suboxone. From the Suboxone providers questioned, those that were part of major corporations had a much more positive attitude towards Suboxone and were willing to take in more Suboxone patients. Therefore, Suboxone needs to be aimed at treatment facilities rather than at individual practitioners, although it was originally aimed at private practitioners. Many of the private practitioners that provided Suboxone did not want to take in more Suboxone patients because they had to deal with a difficult patient population and with patients who "constantly lied, went behind their backs, would not listen to doctors, etc.". Non-prescribers were unwilling to take the certification course or take in patients for the same reason, or because they did not have enough time in their practice to take in more patients. Next, there needs to be more awareness and education for doctors on this issue. Furthermore, many physicians assistants and nurse practitioners are unaware that they can take the certification course to prescribe Suboxone, and that they can obtain 
the DEA (Drug Enforcement Agency) number for providing this treatment drug.

\section{Conclusion}

A major conclusion drawn from this research project is that it is necessary to destigmatize the use of Suboxone by having national, state, and local county societies to endorse its use and emphasize that it is a necessary medical practice. There should also be more outreach to nurse practitioners and physician's assistants to provide this treatment drug, as many are unaware that they could take the certification course. National organizations such as AMA (American Medical Association) and ASAM (American Society of Addiction Medicine) should publicize that it is feasible for these people to take the course. Furthermore, making the 8-hour certification course free online, or even decreasing the required course hours may encourage more providers to take the course. Another conclusion is to have more mental health providers in addiction medicine, who can help opioid addicts with their problems and keep them from relapsing or overdosing. Next, there should be more widespread drug education among doctors. We applaud the recent mandatory opioid course for all doctors in New York State, and recommend that it should be expanded throughout the nation. We also strongly applaud the New York Department of Health's recent Buprenorphine Access Initiative, which discusses about increasing the number of Suboxone providers and improving patient access to this medication in New York. All opioid-prescribing doctors should know how to effectively treat a patient who is found to be abusing the opiate. Finally, more access to inpatient rehabilitation programs needs to be provided to ensure that all patients who need it can be treated.

\section{References}

[1] New York State Senate Majority Coalition. (2016) Executive Summary. Joint Senate Task Force on Heroin and Opioid Addiction.

[2] Norton, E. (2017) Orange County Gov Tackling Opioid Epidemic. The Chronicle. http://www.chroniclenewspaper.com/apps/pbcs.dll/article?AID=/20170501/NEWS0 1/170509990/0/19/Orange-County-gov-tackling-opioid-epidemic

[3] ASAM Staff. (2017) Proposed Patient Limit Raised to 275. ASAM Applauds Important Action to Help Close Addiction Treatment Gap.

https://www.asam.org/magazine/read/article/2016/07/06/asam-applauds-important -action-to-help-close-addiction-treatment-gap.-proposed-patient-limit-raised-to-27 $\underline{5}$

[4] New York State Education Department [Database Online]. (2017) NYSED, New York. http://www.op.nysed.gov/prof/med/medcounts.htm

[5] Indivor [Database Online]. (2016) Indivor, Richmond, VA. https://www.suboxone.com/treatment-plan/find-a-doctor

[6] Vestal, C. (2016) Few Doctors Are Willing, Able to Prescribe Powerful Anti-Addiction Drugs. The Pew Charitable Trusts. http://www.pewtrusts.org/en/research-and-analysis/blogs/stateline/2016/01/15/fewdoctors-are-willing-able-to-prescribe-powerful-anti-addiction-drugs 